Accepted for publication, Juy 2015, Intellectual and Developmental Disabilities

\title{
Can People With Intellectual Disability Resist Implications of Fault When Police Question Their Allegations of Sexual Assault and Rape?
}

Charles Antaki, Emma Richardson, Elizabeth Stokoe, and Sara Willott

$<1>$ Abstract

When people alleging sexual assault are interviewed by police, their accounts are tested to see if they would stand up in court. Some tests are in the form of tendentious questions carrying implications (e.g., that the sex was consensual) damaging to the complainant's allegation. In a qualitative analysis of 19 English police interviews with people with intellectual disability (ID) defined in a variety of ways, we show how people with ID deal with the pragmatic complexity of such tendentious questions. We give examples in which the complainants detect and resist the questions' damaging implications; but we focus on occasions when the complainants do not do so. We discuss the use of tendentious questions in the light of national United Kingdom guidelines on the treatment of vulnerable witnesses.

Key Words: intellectual disability, police, interviews, rape, sexual assault, questions, victims, witnesses 
People with intellectual disability (ID) are disproportionately likely to be the victims of sexual assault and rape (see, e.g., McEachern, 2012, among other sources of documentation in the United Kingdom; and Harrell \& Rand, 2010, for an example of U.S. data). As Petersilia (2001) reports after a survey of U.S. conditions, "few of these crimes get reported to police, and even fewer are prosecuted because officials hesitate to pursue cases that rely on the testimony of a person with a developmental disability" (p. 655).

If the person with ID does report the alleged crime, their dealings with the police, and the legal system in general, can be daunting. Lea, Lanvers, and Shaw (2003) find that, in the U.K., adult rape victims with learning disabilities are overrepresented among cases that drop out of the system. Among the many problems likely to face people with ID in the justice system is communicating their testimony in such ways as to provide sufficient evidence for the police to identify and charge a suspect. If the case proceeds to the courtroom, they will face further communicative challenges, in a still more complex and unfamiliar environment.

Research on people with ID in the U.K. and U.S. criminal justice systems has established that interviewers often fail to take into account the cognitive difficulties experienced by their interviewees (Petersilia, 2001; Royal College of Psychiatrists, 2014). In the U.K., this is acknowledged in guidance given to police interviewers in England and Wales, set out in Achieving Best Evidence in Criminal Proceedings: Guidance for Vulnerable or Intimidated Witnesses, including Children (henceforth $A B E$ ), published by the UK Ministry of Justice (2011). Among other things, it recommends respect for the interviewee, and acknowledgement of their vulnerabilities. It remains to be seen how, and to what extent, police officers in England and Wales follow $A B E$ guidance for complainants who have an intellectual 
disability, whose cognitive difficulties may well be amplified by the particularly sensitive and intimate matters on which they will be questioned, and whose understanding of complex, tendentious questions - those that presume certain unstated premises, and imply certain unstated answers — will be impaired.

\section{$<1>$ Tendentious Questions}

By dint of their inaccessibility, police interviews of suspects and alleged victims have not been subject to a great deal of close observation and research. But there are studies of such interviews, and among them there is evidence that tendentious questions are asked— - both of suspects and, for different reasons, of witnesses. In the case of suspects, it is in the interest of the police interviewer to solicit from the suspect evidence that may reveal (wittingly or unwittingly) the criminal nature of the events they describe, or grounds for one criminal charge rather than another. Stokoe and Edwards (2008), for example, show how an interviewer will ask an ostensibly “"silly question" such as "Did [anon] give you permission to throw the hammer at his front door?" (p. 90). Although the answer will clearly be "no," it nevertheless serves to put on record that the suspect did intentionally throw the hammer at the door, and did so in the knowledge that he had no right to do so; that establishes mens rea necessary for more serious criminal convictions.

In the case of interviews with witnesses, the interest of the police is to test the witness's account both for its evidential worth (in pursuing their investigations and bringing a charge against a suspect) and against likely challenge by defense counsel were the case to come to court. In both cases, police questions must test inconsistencies and vagueness in the witnesses' account, and this can, on occasion, make the questions take a tendentious line. For example, the interviewer may choose 
not only to establish that the complainant did not resist, or did not immediately seek help, but to go further and ask why they did not do so- putting the question in a manner that pragmatically implies that they should have done.

There is ample evidence in the literature that people with ID perform badly in formal situations where they have to use their memory, deal with leading questions, and resist suggestion. In criminal justice settings, the pioneering work of Gudjonsson in revealing problems of acquiescence faced by people with low IQs was extended specifically to people with ID (Gudjonsson, Murphy, \& Clare, 2000), and followed up with a report of similar problems with suggestibility (Milne, Clare, \& Bull, 2002). Crudely summarized, people with ID tend to agree when a yes/no question is put to them, and to assent when a suggestion is made to them. In a police interview, such acquiescent and suggestible tendencies may be problematic for both interviewer and interviewee.

Moreover, many people with autism, even if not necessarily compromised by low IQ, struggle with pragmatics, or what are sometimes called the "social meaning" aspects of language - working out what people mean by nonliteral expressions, indirect questions, or other formulations that require an understanding of others' perspectives (see Perkins, 2010, on pragmatic impairment generally). And people with ID risk being affected by their ordeal emotionally: Rowsell, Clare, and Murphy (2012) show that those with ID at more severe levels reported "marked increases ... in the frequency and severity of a range of emotional, physiological and behavioural symptoms of psychological distress" (p. 263) following the alleged abuse.

All the preceding discussion suggests that the police interview will likely be a difficult communicative experience for the person with ID. The interview is forensic and must consist of questions about events that happened elsewhere, at other times 
(sometimes a long time distant). The interviewer will be testing not only the interviewee's memory, but also the person's credibility as a witness to a crime, and such questioning must sometimes challenge their account when it is vague or inconsistent. As we noted previously, the interviewer will be mindful that should the case reach the court, defense counsel will be alert to any evidence that will help their client's case, and may use question forms that seize on any opportunity to weaken the witness's account. The $A B E$ guidelines foresee this, and mandate that judges "should be alert to the possibility that a witness might be experiencing difficulty in understanding a question which, if not corrected, might lead to the giving of evidence that is not of the best quality that the witness could provide" ( $A B E$, section 5.11). Police officers are nevertheless well aware that the court may not be able wholly to prevent defense counsel from using such questions, or to eliminate their effect on the jury once they have been asked. So to some degree, this interview is a trial run of what the complainant will face under hostile questioning. Some of the questions the interviewer will ask will be pragmatically complex and tendentious - they will imply something blameworthy in the complainant's conduct. It is those questions, and their answers, that we set out to investigate.

\section{$<$ 1 $>$ Data}

Our data come from a police force in England. The force in question tasked an officer to find the 20 most recent interviews from archived cases (i.e., cases not currently still under investigation, at court stage, or otherwise "live"). This force does not record intellectual disability on their computerized database, so all records of rape, attempt rape, or sexual assault in the region were called up and manually checked for the involvement of complainants who were judged to have what was termed a "learning 
disability." The 20 cases identified by this search were dealt with between 2010 and 2013, in one big-city station, by different officers.

It ought to be noted that our police contacts reported that the term "learning disability" is used loosely by this force (and, it was implied, by police forces in the country generally). A witness would be termed "learning disabled" on the basis of their own self-description, or that of a family member or a responsible adult (e.g., a social worker or teacher supporting the person); or, if none of these were available, by dint of local officers' own inference based on information provided by the person (e.g., what school they went to) or by the person's ability to comprehend questions and articulate answers. In some police forces in England and Wales, a standardized questionnaire is used, but not at this station.

In terms of what description is then entered on the case notes, this is extremely brief. In our sample, the description ranged from one word (“Autism”) to 20 (“Impaired intellectual development, mental health issues, sec 2 mental health, self harm. Attends special school for people with learning difficulties"), with most descriptions (13) consisting of 6 words or less. Note that this is the information that would be available to the Crown Prosecution Service (CPS), at the point when they evaluated the evidence for possible bringing to court.

The objective of the interview is to yield evidence as to whether a crime has been committed; which crime it is; what lines of inquiry would need to be pursued to identify the perpetrator and determine whether a charge could be brought; and more relevant to our purpose here, to gauge the evidential strength of the complainant's account as a witness to events. (Note: Appendix A shows the legal definitions of rape and sexual assault in England and Wales at the time of the research; those definitions, 
and criminal justice procedures for detecting and prosecuting them will, of course, vary in different jurisdictions.)

Nineteen of the 20 tapes could be analyzed. Interviews lasted between $21 \mathrm{~min}$ and just over $2 \mathrm{hr}$. The tapes were visually and aurally anonymized before leaving the police station, and pseudonyms have been used in the examples extracted from the transcripts presented in this article.

\section{$<1>$ Analysis}

The method we use is Conversation Analysis (CA), a qualitative method which identifies people's actions in the details of the choice of words, grammatical structure, timing, delivery, and sequence of their utterances. With an extensive base in everyday conversation among people with typical development, it has been used in analysing interactions involving people with ID since the 1980s (for a history and overview, see Antaki and Wilkinson, 2013). Its strengths for our purposes are its close attention to the exact ways in which people speak, and to the otherwise potentially overlooked implications of what they say and how they say it. Elsewhere (Antaki et al, 2015) we have used CA to examine the appearance, in these interviews, of two formats that are especially pragmatically complex (Why didn't you do X? and How come you did X?). In this article the focus is on the how the complainants cope with those and other tendentious questions, and we use CA to describe how complainants resist the questions' implications - or, as we shall see, how they sometimes fail to do so.

In the spirit of accessibility, we have kept some of the analytic concepts "below the surface," as it were, and avoided technical terms that might interfere with the clarity of our analysis. We begin with examples of complainants' successful 
rebuttal of blame-worthy implications in the police officers' questions, then move on to examine their less successful answers.

\section{$<$ 2>Interviewees' Successful Rebuttal of Implications}

Despite their cognitive limitations, complainants with ID were indeed on occasion able to rebut or resist damaging implications. The first example shows the complainant's resistance to what the question implies is her implausibly inconsistent account of the details of the alleged rapist's behavior. It comes after the complainant has established her account, and the interview is in the "probing" phase. In this and the rest of the examples, "P" stands for police interviewer, and "C" for complainant. The symbols used in the transcript are conventional CA notation to try and capture the significant details of speech (e.g., "(0.2)" is a short pause in speech of about one-fifth of a second)—for a glossary, please consult Appendix B.

[Note to typesetter: In this and other "examples," use Courier or plain text type as indicated, and block indent, align on left]

\section{Example 1 Interview 3 [complainant's condition recorded as “Autism"]}

\section{Gypsy dress}

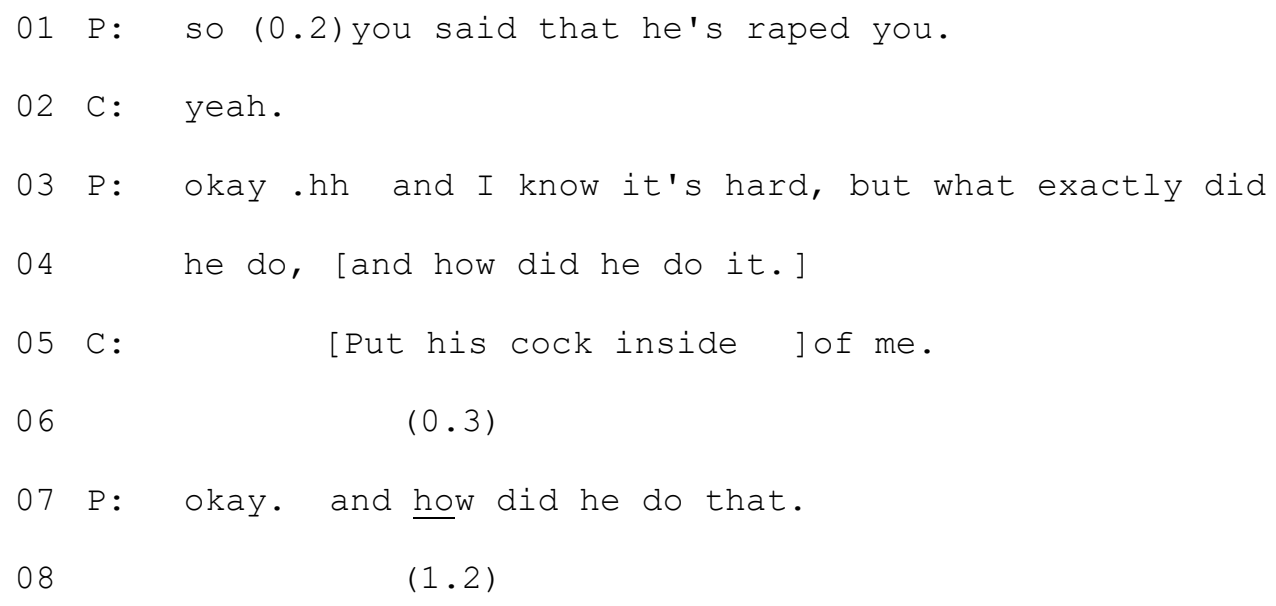




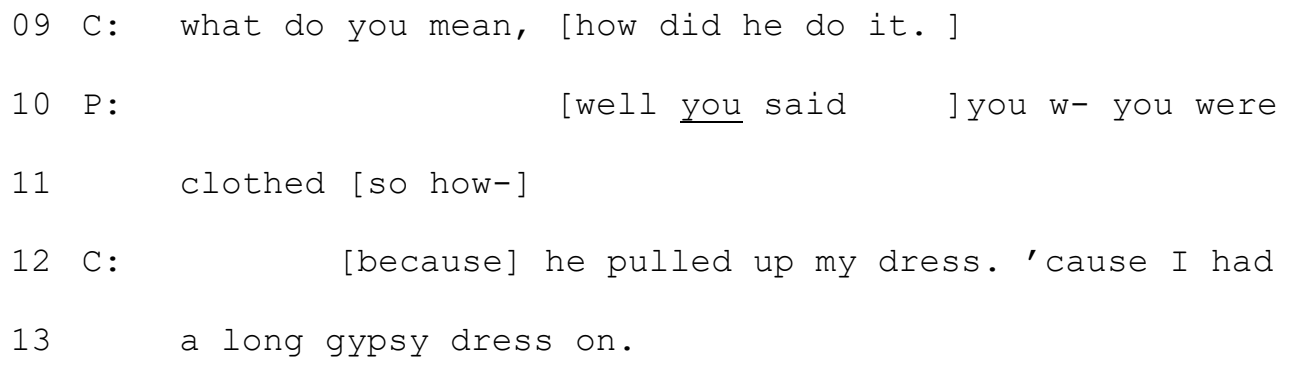

The alleged inconsistency is in the complainant's physically impossible claim that the assailant put his cock inside her while she was fully clothed. The response to note is in line 12/13. To lead up to it: The police interviewer's question in line 7 apparently asks for a physical account of the mechanics of the rape, but the interviewee, after a pause signalling some sort of problem gives (in line 9) a challenging response. This solicits a clearer specification by the interviewer (line 10), but it is not a neutral one. The officer designs it in three ways to imply fault: it is prefaced by well, indicating trouble with the complainant's response; it grounds the repaired question in the complainant's own words (you said...), and it uses the causal connective so to imply a disjunction between what she had said and the facts she now claims. This is cut off by the complainant, presumably predicting the question so how could he put his cock inside of you when you had all your clothes on? or its equivalent.

The implication is at the very least that the complainant is confused, and at worst that she has been caught out in a lie. The interviewee is alive to this, however, and issues an answer that, by revealing that he had pulled her dress up (and giving some ostensibly supporting evidence the details of the dress) deletes the physical impossibility that the interviewer's question had implied.

The next example shows resistance to an implication that the complainant had sexual desires that may have contributed to the unfolding of the events. 
[block indent, again]

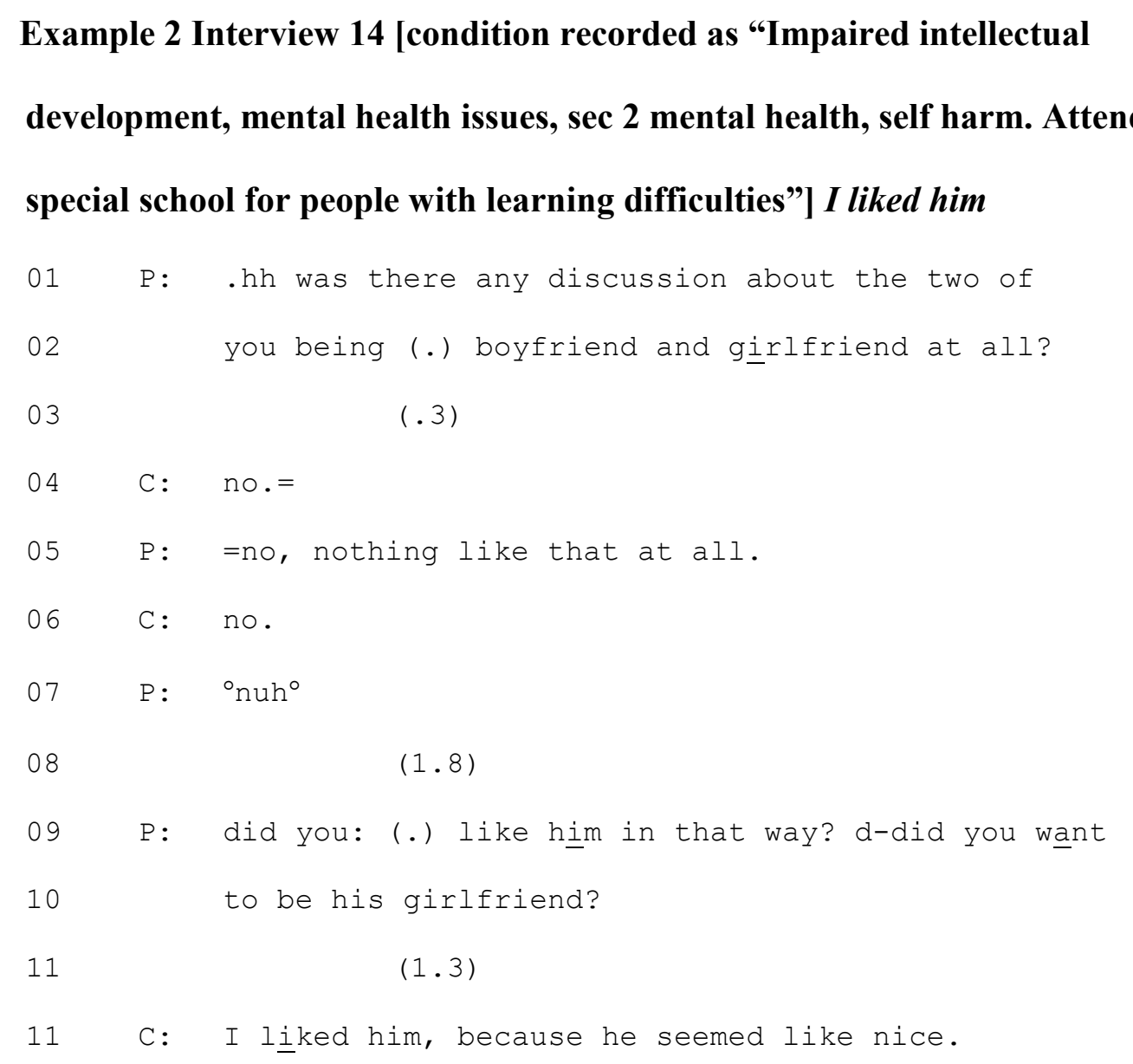

The police interviewer's question at lines 1-2 implies, or at least provides for, the complainant having some sexual desire for the man who allegedly became her assailant. Whether the victim "liked [her assailant] in that way" would be argued by the prosecution to be irrelevant to the question of whether she consented to sex on the occasion under dispute (indeed, Macleod [2010] in an investigation of similar interviews calls it a "rape myth"). Nevertheless it is the kind of question that defense counsel might use to mobilize the argument that if it could be shown that the victim found the man sexually attractive, then it was likely that the sex was consensual. Our concern here is to show that the complainant does successfully rebut the implication 
of "in that way" and wanting to be "his girlfriend" by asserting a more cautious, and less sexualized reason for liking him-he seemed like nice.

\section{$<$ 2>Interviewees' Failure to Rebut Implications of Fault in Questions}

The two previous examples showed that, despite their cognitive limitations, complainants with ID can at least sometimes identify and disarm damaging implications in police questions. But this was not always the case in our data. In this section we give examples of their difficulties with challenging questions designed to test the complainant's account in what are taken to be significant areas: their general sexual history; their behavior leading up to the alleged assault; and their resistance during it.

$<$ 3> Sexual history. Questions about the complainant's understanding of sex are meant to find out if the complainant understands the experience that they are reporting, and is able accurately to identify genitalia and bodily functions like ejaculation. Questions are also asked about the sexual relationship between complainant and alleged assailant — a legally arguable concern in its own right—but on occasion the questions stray into inquiries about the complainant's sexual history in general. In the following example, note the long gaps between the interviewer's question and the complainant's answer.

[block indent]

Example 3 Interview 10 [Condition recorded as "severe learning difficulties. Assessed as functioning age of 5 yrs old so interviewed a 2nd time with intermediary"] Porn

01 P: I kno:w in the past it's been spoken about that 
04 P: Did you ever watch porn when you were living at 05 home?

$06 \rightarrow \quad(3.9)$

07 P: It's oka:y. Remember we need to be truthful.

[P establishes that the complainant understands what "porn" means]

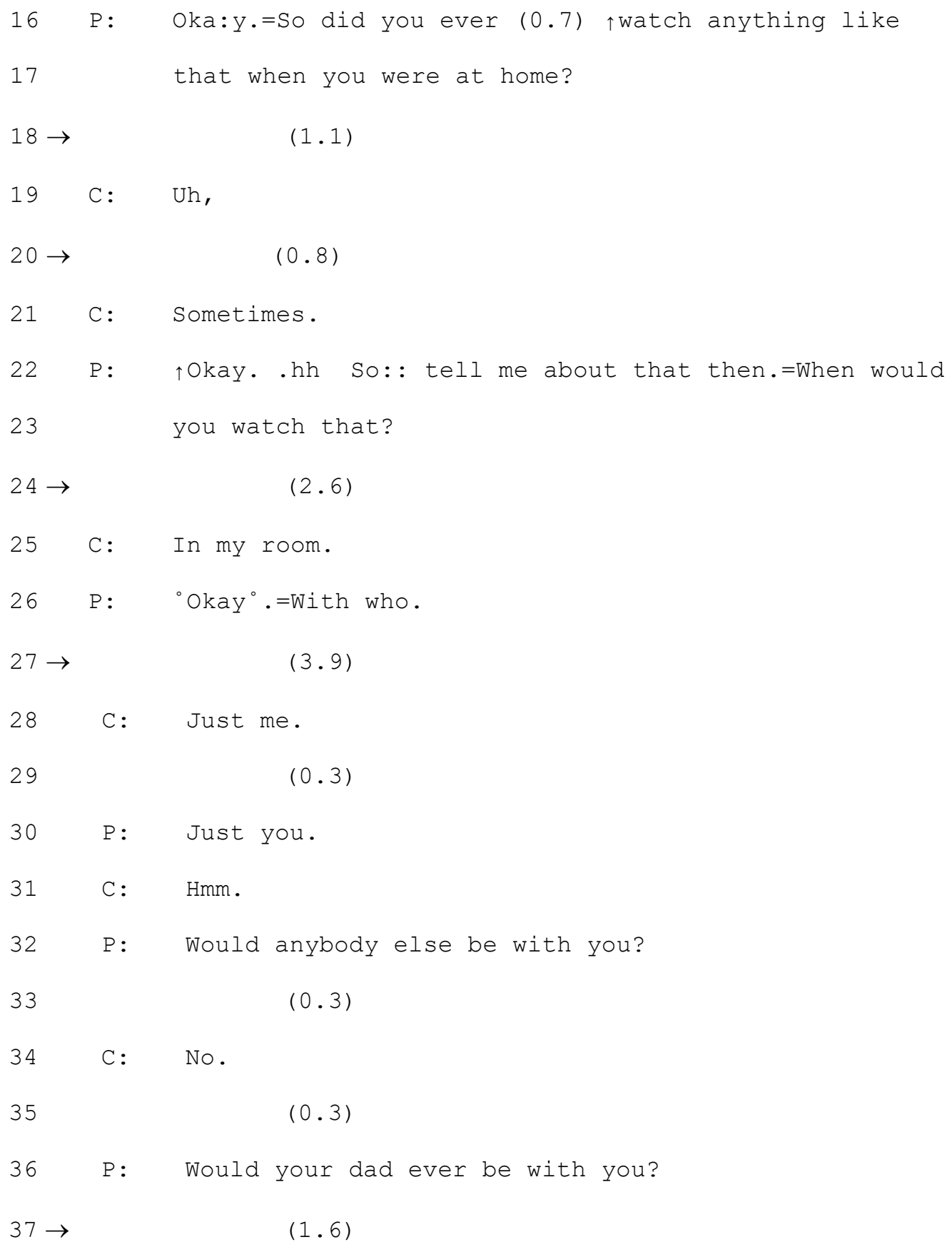




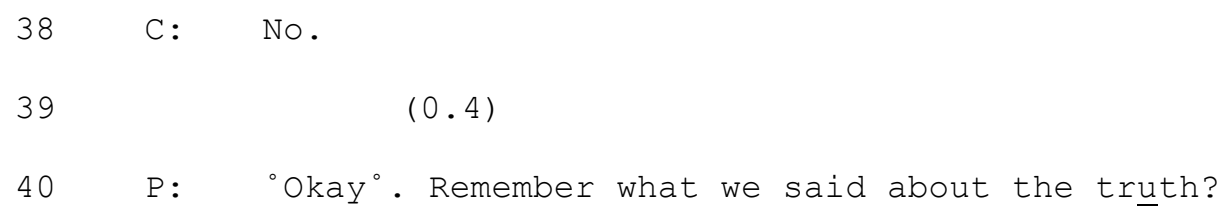

The rhythm of turns in the interview up to this point was, as is typical of conversation in general, a "beat" of much less than $1 \mathrm{~s}$. Longer pauses are consistent with a response indicating some trouble with the reply. The kind of pause between the interviewer's question and her answers at lines 5, 18/20, 24, 27, and 37 could be taken to index uncertainty (or worse). Given that knowing whether you have watched porn, and with whom, could reasonably be taken to be the kind of knowledge anyone should be able to access very quickly, a delay appears to be accountable. Indeed, the police interviewer treats it as such, by reminding the complainant at two points that it was important that she tell the truth. In sum, the complainant's failure here is to misjudge the interactional meaning of the pauses between blame-implicative question and her answer.

$<3>$ Choices and behavior leading up to the alleged assault. The tendentious questions here concern the events that preceded the alleged assault. In the following example, the interviewer is probing the complainant's response to her alleged assailant's request for sex.

[block indent]

Example 4 Interview 14 [condition recorded as "Impaired intellectual development, mental health issues, sec 2 mental health, self harm. Attends special school for people with learning difficulties"] Just come on

$01 \quad P$ : did he say anything else.

$02 \quad(1.2)$ 


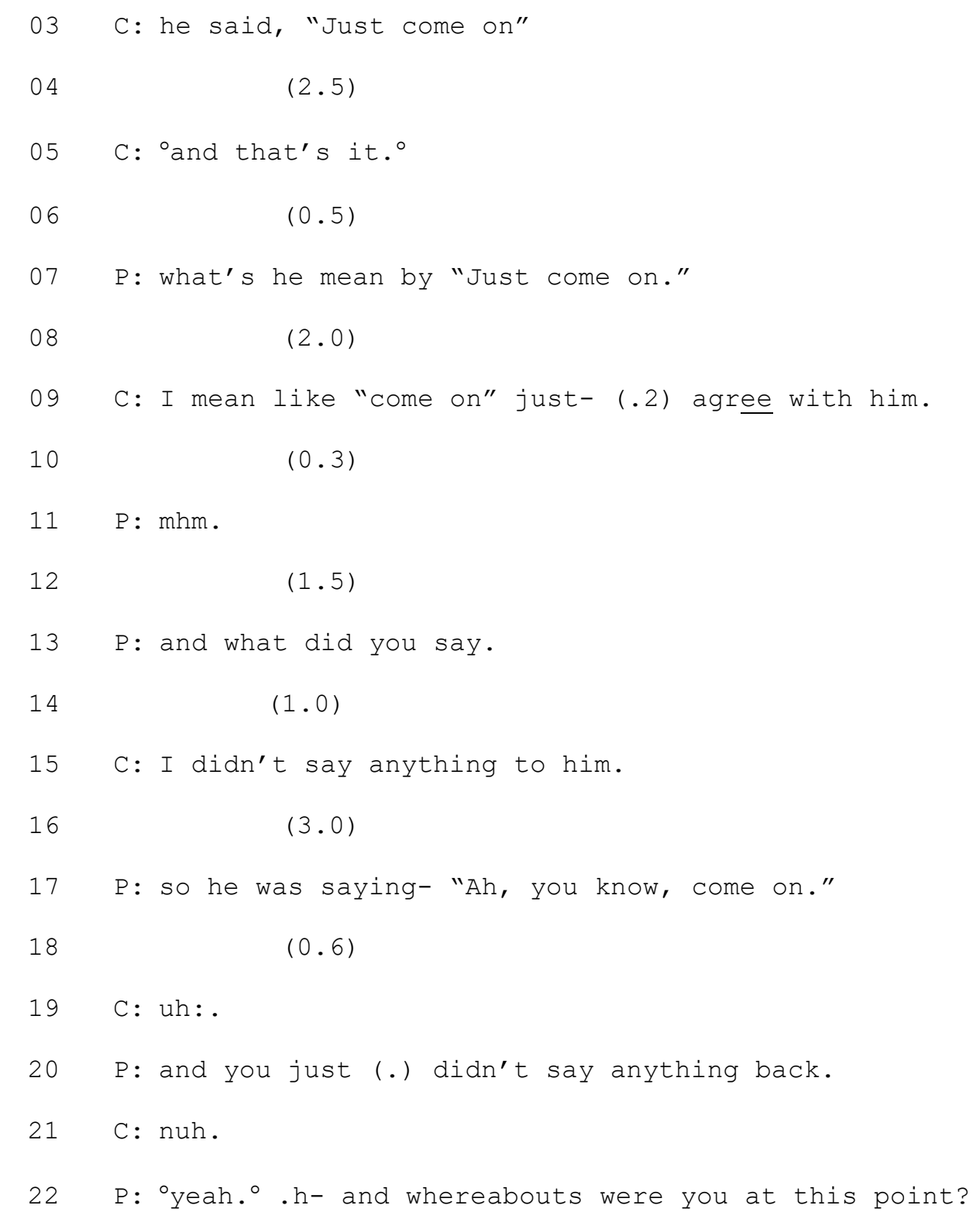

Immediately before the start of the extract, the interviewer had summarized the complainant's account so far and established that she had "said no" to his request for sex. At line 1 she enquiries further into the development of the conversation, and the complainant answers that he said come on or just come on. The interviewer asks whether she responded to this and gets what appears to be the firm answer that the complainant didn't say anything to him (line 15). At this point the interviewer issues a compound question (lines 17-20) is in the pragmatically tendentious format of so he did $X$ and you just did $Y$ ? (Compare, for example, merely accepting the complainant's 
reply, or if pursuit was necessary, asking more neutrally were there any other words exchanged or words to that effect.) The complainant's no does nothing to reject the premise that her silence requires accounting for. The implication remains that her failure to reject sex was notable and requires explanation.

$<3>$ Resisting the alleged assault. In the following cases, the interviewer asks the complainant a question about a key moment in the alleged assault once it had started: why she didn't call out for help, or otherwise resist. We note that resistance is amenable to different interpretations: On the one hand, evidence that the victim struggled, and had to be restrained, would be consistent with allowing the police to bring a charge involving violence. But on the other hand, evidence that the complainant did not struggle would be seized on by defense counsel as showing that the sex was consensual and that the events were not rape, or assault. In Examples 5 and 6, the complainant responds that she "doesn't know" why she did not resist.

[block indent]

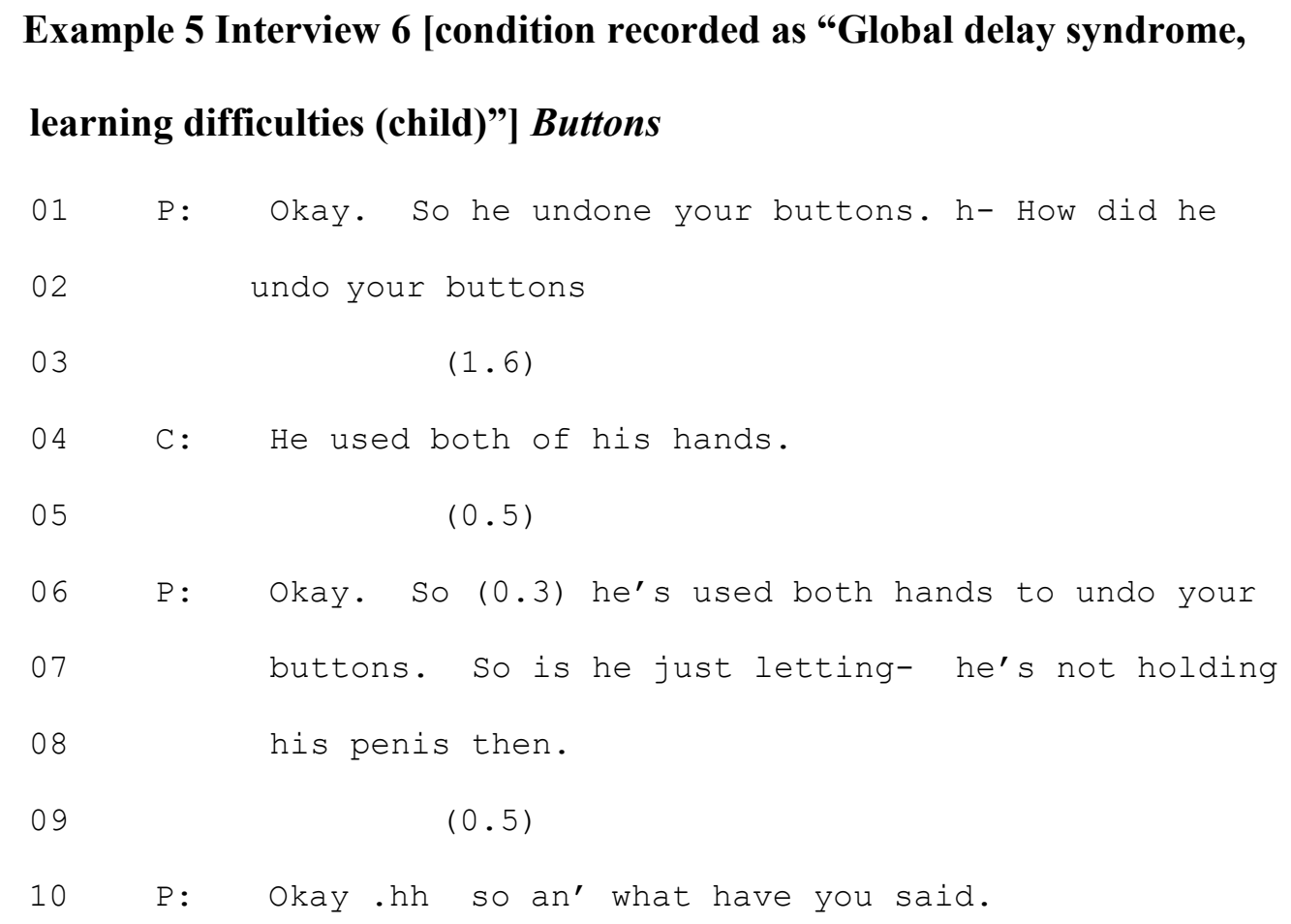




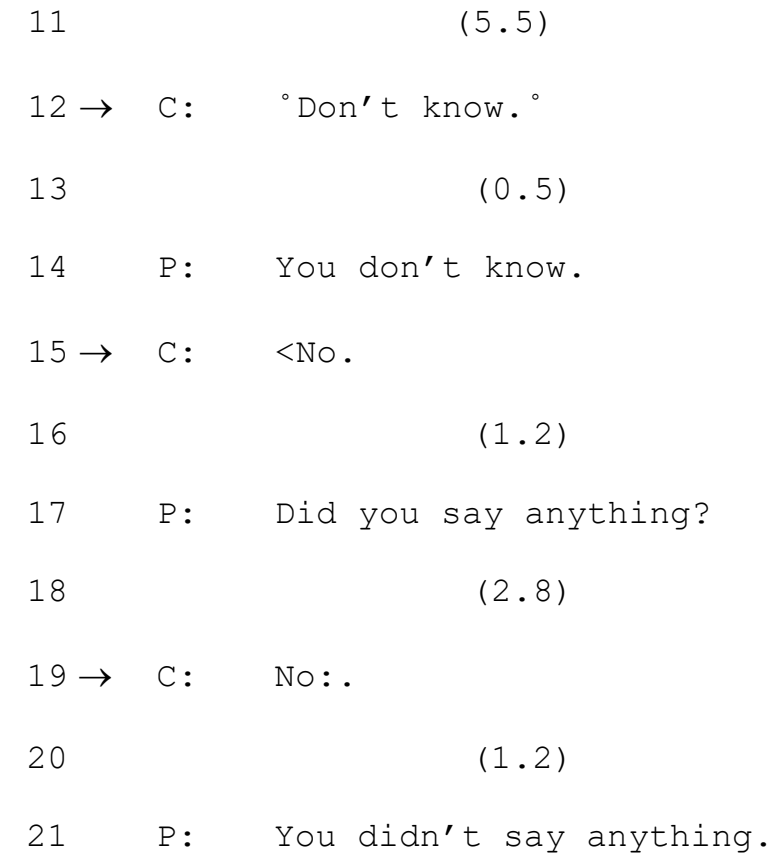

In example 5, the interviewer had previously established that the complainant had been backed against a wall against her will. The summary of events (lines 6-8) is one that would normatively prompt some sort of protest, solicited by the interviewer's question at line 10. Note the interviewer's use of the consequential conjunction so, making emphatic the implication that the complainant's actions are to be judged as their response to the alleged assailant's action. In a delayed response, the complainant first claims not to know what she said, then, on being pressed, denies saying anything. This allows the implication of lack of resistance, and possible consensuality, to stand.

On occasion, the interviewer would pursue a fault-implicative question in spite of the complainant having already given a plain and confident fault-denying answer. In example 6, as follows, the complainant gives a clear answer to the question why she didn't say anything to her assailant ([he] probably would have had a go at me), but the interviewer reformulates this answer and queries it.

[block indent] 


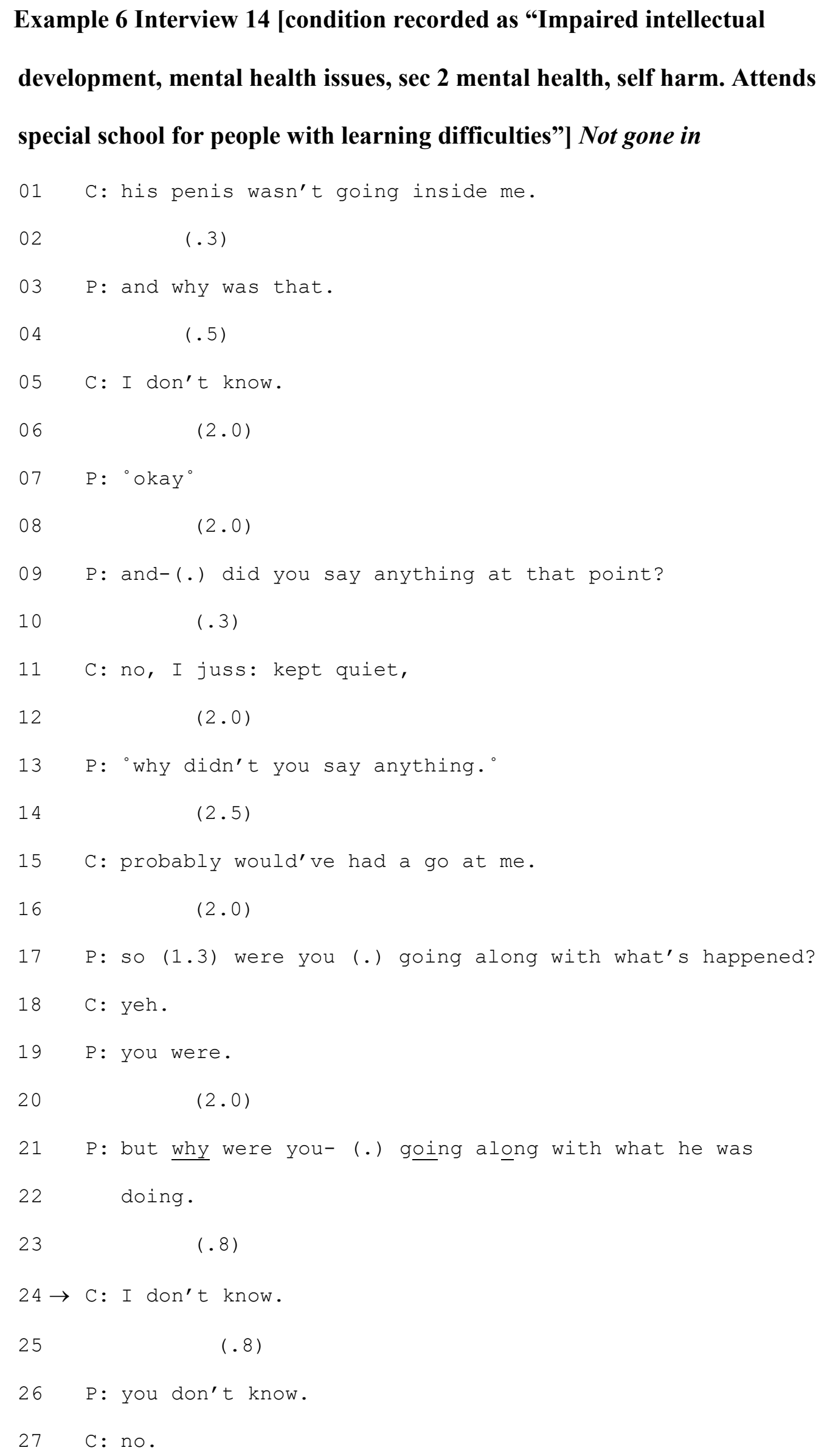


At line 21 the interviewer uses the disjunctive preface but why ... to query the complainant's inaction, in spite of what would appear to be a normatively acceptable fear of violence. Repeated questions to people with ID can cause them to infer that their original answer was mistaken or faulty, and thereby change it (see Finlay and Antaki, 2012). This seem to happen here, with the complainant at line 24 declining to restate her fear of the assailant's violence, and having recourse to "not knowing" why she allowed him to carry on trying to put his penis inside her. Again, as in example 5, this allows the implication of possible consensuality to stand.

The questions in examples 5 and 6 were responded to by the complainant asserting that she didn't know why she acted as she did. It would also happen that the complainant responds to a tendentious question about her resistance with a more complex answer, or answers, which fail to delete its implications. In example 7, the complainant gives contradictory information to the question why didn't you scream then? We join after "P" has established that the complainant's caregiver "Sharna" and her baby weren't in the house, but other people, who might have helped, were there. The transcript extract is necessarily rather long to reveal the contradictory replies.

\section{[block indent ]}

Example 7 Interview 20 [condition recorded as “ $\mathrm{LD}$, partially sighted, hearing problems, special school"] Loved him

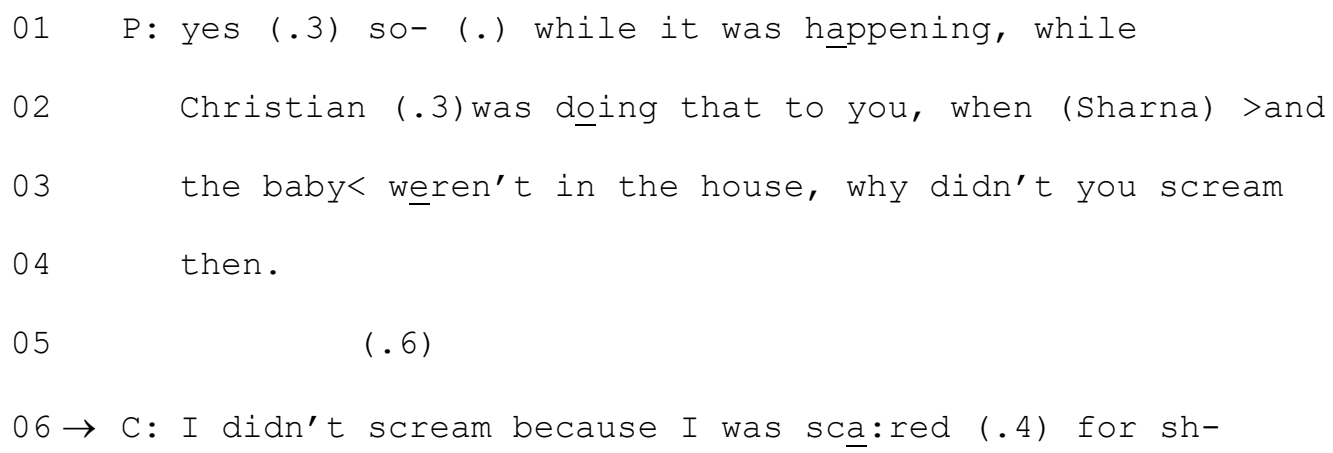




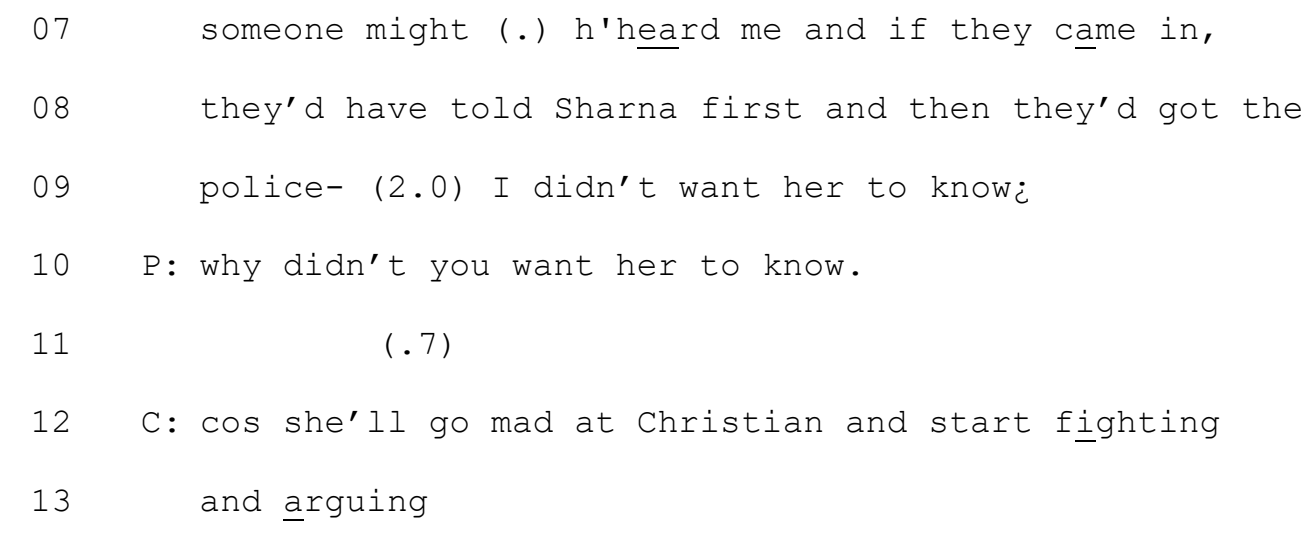

[about 30 s skipped, in which $\mathrm{F}$ describes

Christian's violence when arguing with Sharna]

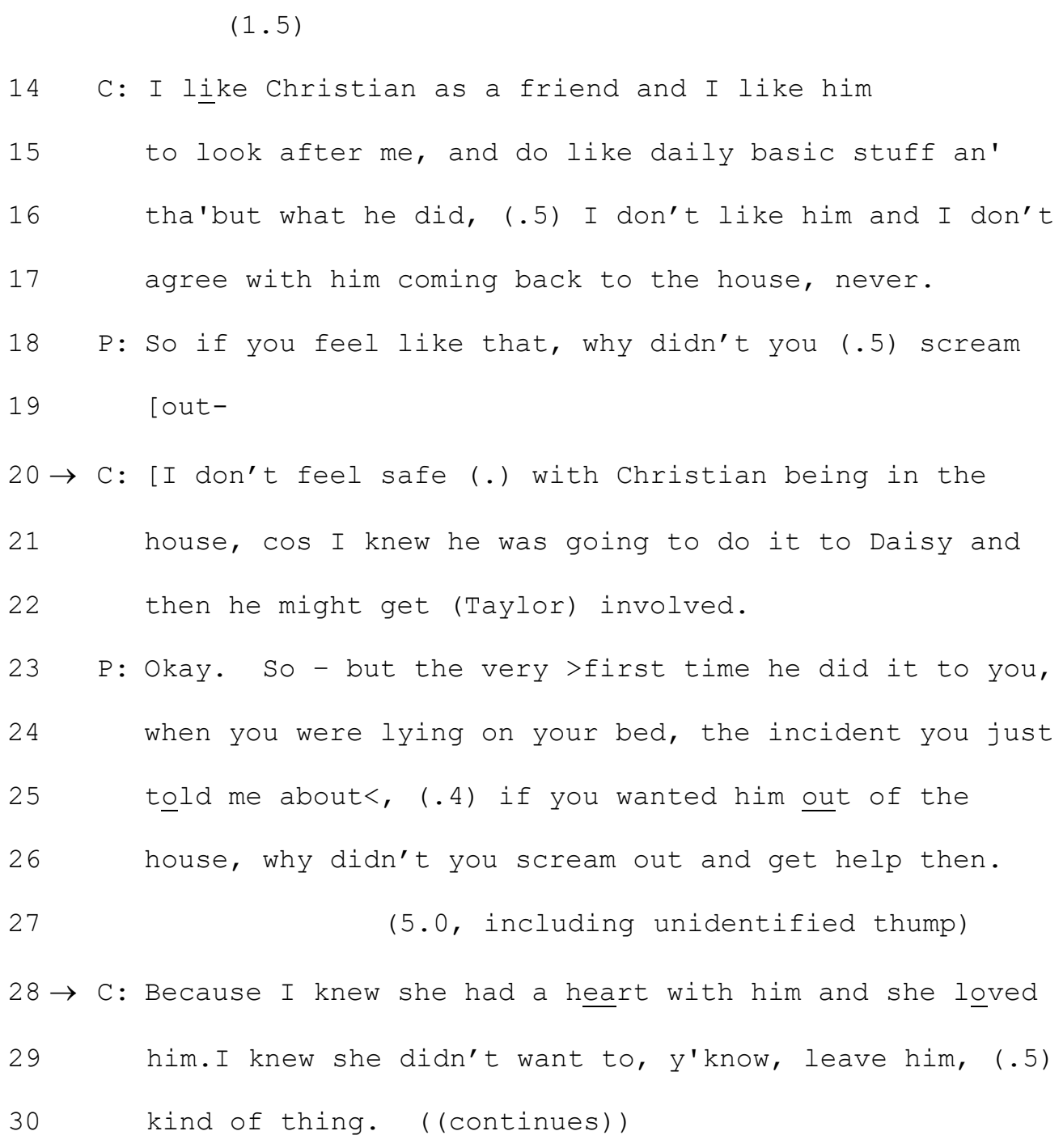

The complainant's first explanation (lines 6-18) for not screaming is that she feared that her caregiver Sharna and the police would be informed. P's follow-up query (line 
10) as to why this would matter elicits a report that Sharna would go mad at

Christian, and this develops into an account (not shown) of Christian's violence and the complainant's negative feelings toward him.

The interviewer asks again why, if F didn't (implicitly, why she didn't even) want him around the house, she didn't scream for help while being raped. At this point F might have repeated her earlier answer (that Sharna would suffer Christian's violence), but instead offers something that is not well formatted as an answer (lines

20-22). Rather, it seems to avoid the question and reassert her suspicion of Christian's behavior, and include others as potential victims. The interviewer does not topicalize this potential new avenue, and reissues the question again (line 26). Note the if-then construction of the question, which, like the so construction in example 7, emphasizes the background against which the complainant's actions are to be assessed.

Once more the complainant forgoes restating or elaborating her original answer, and instead answers in terms of Sharna's relationship with Christian. This is not easy to understand as an answer to the question, but may represent the argument that if Christian got into the kind of trouble that would entail separation, it would distress Sharna, which the complainant did not want to happen. In sum, she has changed her reason for not screaming for help twice - originally it had been the (plausible) fear of causing an argument which would unleash her assailant's violence, but on repeated questioning it mutated into, first, a hint that he might endanger other children, and second, that her caregiver would be upset. Such changes might be taken by the police to render the complainant an "unreliable witness" in court, and would be seized on by defense counsel, if it got that far. 
As we noted in the introduction to this article, research in the United Kingdom and the United States has shown that people with ID — whether as alleged offenders or alleged victims — often do not fare well in the criminal justice system (see, e.g., Petersilia, 2001; Royal College of Psychiatrists, 2014). Our focus in this study was on the treatment of a sample of people with ID alleging that they victims of sexual abuse. In such cases, what witnesses say in interview is usually crucial in establishing whether a crime has been committed against them and whether a charge can be brought; and especially in the case of sex crimes, whether the witness is credible and themselves not culpable. The aim of this study was to examine whether a sample of people with ID could identify incriminating implications of tendentious questions in police interviews, and design answers that deleted them.

We found that tendentious questions tended to come up at points in the narrative which were crucial for the police in determining whether the charge of sexual assault or rape would stand up in court: the complainant's sexual history (especially, their history with the alleged assailant); their choices and behavior leading up to the alleged assault; and their resistance during it. A complainant's case is perceived by the police to be weakened if the complainant can be revealed to be a consensual partner. Hence the probe —often repeated and insistent —of the exact details of the events, and the alleged victim's exact part in it.

Our sample of alleged victims with ID described in a variety of ways (patchily-recorded) sometimes could resist the implications of the question, but sometimes could not. When they did not, their don't know answers, and their changed answers, failed to delete such implications as that they made (what defense counsel might argue were) imprudent or unwise choices (e.g., not making their refusals insistent enough), or failed unaccountably to resist their alleged assailant's advances 
once they were underway (e.g.,, by not protesting when he unbuttoned their trousers, or not calling out when they knew that there was possible help at hand). Such failures would, in court, damage the prosecution case. It is a moot point, of course, whether the alleged victim's answers are a matter of them failing to see the false implications of a question, and answering inadvizedly, or a matter of the question's implications being true, and the answer simply being honest. Perhaps; we cannot know. But we can at least say that such failures at this stage might discourage the police from passing the case on to the CPS. Indeed, only three of the 20 cases made available to us came to court (of which two resulted in a guilty verdict).

More positively, it should be said that the interviewers did, on occasion, show sensitivity to the complainant's limited cognitive powers, by allowing time for the incautious answer to such tendentious questions to be repaired. If an interviewee became distressed, the interviewers generally managed the demanding requirements of supporting the interviewee on the one hand, and continuing the impersonal, forensic demands of the interview on the other (Antaki et al, 2015).

It is these more sensitive practices that are mandated by the U.K. guidelines Achieving Best Evidence. The require that "where there are concerns that a witness has a learning disability, even if the extent of the disability is considered to be relatively mild, it is essential that a great deal of care is taken in framing questions and evaluating the witness's response to them" ( $A B E$, section 28, UK Ministry of Justice, 2011). The qualitative evidence that we have assembled here suggests that such guidelines are not always being followed, and that more care should be taken in exposing complainants with ID to questions that imply their own culpability in acts of sexual assault. 
Antaki, C., Richardson, E, Stokoe, E.H. and Willott, S. (in press) Police interviews with vulnerable people alleging sexual assault: probing inconsistency and questioning conduct. Journal of Sociolinguistics, forthcoming

Antaki, C., Richardson, E., Stokoe, E and Willott, S. (2015) Dealing with the distress of people with intellectual disabilities reporting sexual assault and rape. Discourse Studies, 17, 1-18 http://dx.doi.org/10.1177/1461445615578962

Antaki, C. and Wilkinson R. (2012) Conversation Analysis and the Study of Atypical Populations. In T Stivers and J Sidnell (Eds.) Handbook of Conversation Analysis . Blackwell-Wiley, pp 533-550 http://dx.doi.org/10.1002/9781118325001.ch26

Crown Prosecution Service (CPS). (2012). CPS policy for prosecuting cases of rape. Retrieved from http://www.cps..gov.uk/publications/prosecution/rape.html\#_02 [accessed June 2014]

Finlay, W. M. L., \& Antaki, C. (2012). How staff pursue questions to adults with intellectual disabilities. Journal of Intellectual Disability Research, 56, 361370. http://dx.doi.org/10.1111/j.1365-2788.2011.01478.x

Gudjonsson, G. H., Murphy, G. H., \& Clare, I. C. H. (2000). Assessing the capacity of people with intellectual disabilities to be witnesses in court. Psychological Medicine, 30, 307-314. http://dx.doi.org/10.1017/S003329179900149X

Harrell, E., \& Rand, M. (2010). Crime against people with disabilities, 2008.

Washington, DC: U.S. Department of Justice, Office of Justice Programs, Bureau of Justice Statistics. Retrieved from http://bjs.ojp.usdoj.gov/content/pub/pdf/capd08.pdf [accessed June 2014] 
Lea, S., Lanvers, U., \& Shaw, S. (2003). Attrition in rape cases: Developing a profile and identifying relevant factors. British Journal of Criminology, 43, 583-599. http://dx.doi.org/10.1093/bjc/azg583

MacLeod, N. J. (2010). Police interviews with women reporting rape: A critical discourse analysis. Unpublished PhDdissertation, School of Languages \& Social Sciences, Aston University. Retrieved from http://eprints.aston.ac.uk/15206/ [accessed June 2014]

McEachern, A. G. (2012). Sexual abuse of individuals with disabilities: Prevention strategies for clinical practice. Journal of Child Sexual Abuse, 21(4), 386-398. http://dx.doi.org/10.1080/10538712.2012.675425

Milne, R., Clare, I. C. H., \& Bull, R. (2002). Interrogative suggestibility among witnesses with mild intellectual disabilities: The use of an adaptation of the GSS. Journal of Applied Research in Intellectual Disabilities, 15, 8-17. http://dx.doi.org/10.1046/j.1360 2322.2001.00096.x

Perkins, M. (2010). Pragmatic impairment. In J. S. Damico, N. Müller, \&b M. J. Ball (Eds.), The handbook of language and speech disorders. Chichester, UK: Blackwell. http://dx.doi.org/10.1002/9781444318975.ch10

Petersilia, J. (2001). Crime victims with developmental disabilities: A review essay. Criminal Justice and Behaviour, 28, 655-694 http://dx.doi.org/10.1177/009385480102800601

Rowsell, W. L., Clare I. C. H., \& Murphy, G. (2012). The psychological impact of abuse on men and women with severe intellectual disabilities. Journal of Applied Research in Intellectual Disabilities, 26, 257-270.

http://dx.doi.org/10.1111/jar.12016 
Royal College of Psychiatrists. (2014). Forensic care pathways for adults with intellectual disability involved with the criminal justice system. London, UK: Author.

Stokoe, E., \& Edwards, D. (2008). "Did you have permission to smash your neighbour's door?" Silly questions and their answers in police-suspect interrogations. Discourse Studies, 10(1), 89-111. http://dx.doi.org/10.1177/1461445607085592

UK Government (2003) Sexual Offences Act, 2003. Retrieved from http://www.legislation.gov.uk/ukpga/2003/42/section/1?view=extent [accessed June 2014]

UK Ministry of Justice (2011) Achieving Best Evidence in Criminal Proceedings. London: HMSO http://www.justice.gov.uk/downloads/victims-andwitnesses/vulnerable-witnesses/achieving-best-evidence-criminalproceedings.pdf [accessed June 2014]

Received 1/5/2015, accepted 6/17/2015.

We are grateful to Helen Edwards for legal guidance on this matter, though any fault in interpretation is our responsibility.

\section{Authors:}

Charles Antaki, Emma Richardson, and Elizabeth Stokoe, Department of Social Sciences, Loughborough University, Loughborough, United Kingdom; and Sara Willott, Birmingham Community HealthCare NHS Trust, Learning Disability, Psychology Services, The Greenfields, Birmingham, United Kingdom. 
Address correspondence concerning this article to Charles Antaki, Department of Social Sciences, Loughborough University, Loughborough, LE11 3TU UK (e-mail: c.antaki@Lboro.ac.uk).

$<$ 1>Appendix A: Legal Definitions of Rape and Sexual Assault, England and Wales

1. Rape (selected provisions)

“(1) A person (A) commits an offence if-

(a) he intentionally penetrates the vagina, anus or mouth of another person (B) with his penis,

(b) B does not consent to the penetration, and

(c) A does not reasonably believe that B consents.

(2) Whether a belief is reasonable is to be determined having regard to all the circumstances, including any steps A has taken to ascertain whether B consents."

2. Sexual assault (selected provisions)

“(1) A person (A) commits an offence if-

(a) he intentionally touches another person (B),

(b) the touching is sexual,

(c) B does not consent to the touching, and

(d) A does not reasonably believe that B consents.

(2) Whether a belief is reasonable is to be determined having regard to all the circumstances, including any steps A has taken to ascertain whether B consents."

[Note to typesetter: note used of Courier font and ASCII text in this appendix] 


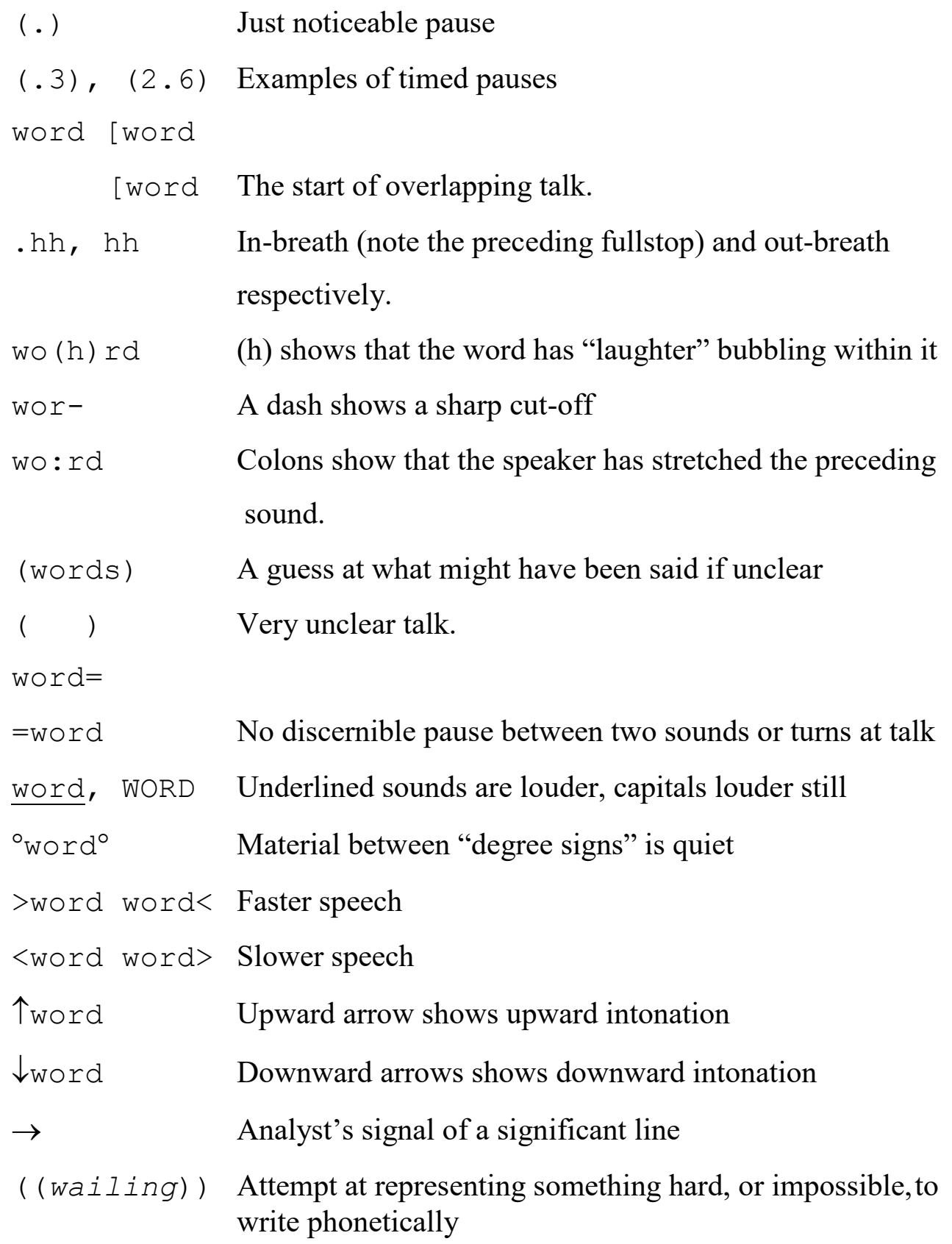

